\title{
Validation of 14 Carbon-Urea Breath Test for the Diagnosis of Helicobacter Pylori Infection in Patients Attending National Center for Early Detection of Cancer.
}

\author{
Maral F. Thabit (F.I.C.M.S.FM) ${ }^{1}$, Muntadher K. Mahmood (MB.Ch.B) ${ }^{2}$, Hani \\ Al- Ansari (F.I.C.M.S/GSC.A.B.S) ${ }^{3}$ \\ ${ }^{l}$ Community Health department, Institute of Medical Technology, Baghdad, Iraq. \\ ${ }^{2}$ Bab Al Muthum Primary Health Care center, Baghdad, Iraq. \\ ${ }^{3}$ Surgical department, Baghdad Teaching hospital, Baghdad, Iraq.
}

\begin{abstract}
The bacterium Helicobacter pylori (H. Pylori) has a high prevalence of up to more than 50\%, especially in developing countries and this bacteria play role in many human diseases, especially duodenal ulcers, gastric ulcers and stomach cancer. The 14 carbon- urea breath test (14C-UBT) help in diagnosis of infection, this study aims to assess the diagnostic value of Heliprobe (14C-Urea Breath Test) for the diagnosis of H. Pylori infection in patients presented with dyspepsia.

A prospective study was conducted at the National Center for Early Detection of Cancer for the period extending from 18th December 2011 to 18th May 2012 and the study included (74) patients, exceeded the age of (20) years old and of both sexes who had or had not a final diagnosis of H. Pylori infection depending on histological examination [the gold standard test(GS)], were subjected to an interview questions covering aspects of social and clinical characteristics in addition to the conditions of the test.

The total number of patients (74) patients, 26 (35.14\%) were females and 48 (64.86\%) were males, 22 (29.73\%) of patients within the age group (20-30 years),most patients had gastritis, by histological examination results were $49(66.22 \%)$ positive cases and $25(33.78 \%)$ cases were negative, and by test results were 40 (54.1\%) positive cases and $34(45.9 \%)$ cases were negative. The proportion of test sensitivity, specificity, accuracy assessment, the positive predictive value and negative predictive value in patients were (81.63\%), (100\%), (87.84\%), (100\%) and (73.53\%) respectively.
\end{abstract}

Conclusions: The 14C-UBT help in the diagnosis of H. Pylori infection.

Key wards: Validation, 14 Carbon-Urea Breath test, Helicobacter Pylori Infection

\section{Introduction}

H. pylori is a spiral-shaped ,microaerophilic, curved rod, approximately $0.5 \times 3.0$ micrometers in size, oxidase, catalase ,urease positive organism, has 4-6 sheathed flagella attached to one pole that allow motility, gram-negative bacterium that resides in the gastric epithelial mucosa and induces an inflammatory response leading to gastritis and peptic ulcer disease [1,2]. It has been implicated as playing a role in gastrointestinal malignancies, especially gastric adenocarcinoma and (MALToma) until the latter could be treated with $\mathrm{H}$. pylori eradication [3, 4]. H. pylori has a worldwide prevalence rate of about $50 \%$, with a higher prevalence in developing countries $[5,6]$.

H. pylori detection can be made with diverse diagnostic tests, which are technically divided into invasive and non-invasive based on whether endoscopy is required or not. Invasive tests offer the possibility of obtaining tissue samples, which can be used for a RUT, culture, PCR, and histopathologic evaluation. Noninvasive tests include serum $H$. pylori $\mathrm{IgG}$ antibody titer, the UBT, and $H$. pylori stool antigen assay. Compared to non-invasive diagnostic modes, however, invasive techniques are inconvenient for patients and also have higher cost [7]. A UBT diagnostic test is based on the fact that swallowed "labeled carbon-containing urea" is broken down to ammonia and $\mathrm{CO} 2$ by the urease-producing microorganism $\mathrm{H}$. pylori in the gastric mucosa, and, finally, tagged carbon within the liberated $\mathrm{CO} 2$ is detected in exhaled breath samples. The urease enzyme is not present in mammalian cells, so the presence of urease in the stomach is evidence that bacteria are present. The presence of urease is not specific for $H$. pylori, but other bacteria are not usually found in the stomach $[8,9]$. Between two carbon isotopes (13C and 14C), which are used for the UBT, the 13C isotope has the difficulty of requiring more complex equipment, such as a mass spectrophotometer and administration of a pretest meal such as citric acid. However, when the $14 \mathrm{C}$ isotope is utilized, the required equipment is only a portable compact beta-scintillation counter, which offers the convenience of performing the test in the office. Although the $14 \mathrm{C}$ isotope is radioactive, micro dose $(1 \mu \mathrm{Ci}[37 \mathrm{KBq}]) 14 \mathrm{C}$ has the minimal radiation of one day background exposure [10]. 
In Iraq, attempts have been made to use 14C-UBT since 2010 in National Center for Early detection of Cancer as a preferred non-invasive choice for detection of $H$.pylori infection.

\section{Aims of the Study:}

To evaluate the validity of $14 \mathrm{C}$-UBT for the diagnosis of $H$. Pylori infection in patients presented with dyspepsia.

\section{Patients and Methods}

A prospective study was conducted at the National Center for Early Detection of Cancer over a period of five months extending from the 18th of December 2011 to 18th of May 2012.An official permission was obtained from the Director of National Center for Early Detection of Cancer prior to the final approval of Ministry of Health to conduct this study. Data was collected after informed consent was received from the included patients.

The study sample had been selected from patients who attended to the study place referred from private and outpatient clinics. Seventy four consecutive patients above the age of twenty years and of both sexes presented with dyspepsia were included in this study. Patients who had history of taking antacids, PPIs and H2RAs within last 2weeks, antibiotics use within the last four weeks prior to the endoscopic evaluation, history of gastric surgery, non fasting, pregnant or lactating women, children, a previous diagnostic 14C-UBT within the last 30 days and those who had no histopathological results were excluded from the study.

A specially designed questionnaire is filled for each patient including general information regarding socio-demographic characteristic, origin of case referral, duration of symptoms, symptomatology of disease, history of medication use; previous gastric surgery and pregnancy or lactation, the results of breath test; endoscopy and histological examination. The procedures were done by the same and well trained health workers, well calibrated and standardized procedures for all included patients.

After an overnight fasting, patients underwent gastroscopy, and gastric biopsies were taken for histopathological examination. Tissue samples were prepared with standard H\&E for histo-pathologic investigation. After gastroscopy, Heliprobe 14C-UBT tests were performed, the patient swallowed a 14C-labeled ureacontaining capsule (Helicap) with water. The overall activity of these capsules is as small as $1 \mu \mathrm{Ci}(37 \mathrm{KBq})$. After 15 minutes, the patient breathed out into a dry cartridge (Heliprobe breath card) through its mouthpiece until the color of the card indicator changed from orange to yellow, which last about $1 \mathrm{~min}$ to $2 \mathrm{~min}$. Thereafter, the breath card was inserted into a small desktop Geiger Müller counter (Heliprobe Analyser), and the radioactivity of the breath samples was read after 250 seconds of an automated process. Finally, the test results were expressed on the liquid-crystal display(LCD) of the analyzer in a numeric fashion and corresponded to radioactivity as count per minute(CPM) as follows:

0: patients were considered not to be infected: <25 CPM

1: borderline results: $25-50 \mathrm{CPM}$

2: patients were considered infected: >50 CPM.

In this study, Grade 1 was not reached, and for the purpose of statistical analysis ,the patients were categorized into two group:

Group 1 (grade 0); consist of patients having 14C-UBT as negative

Group 2 (grade 2) ; consist of patients having 14C-UBT as positive.

The collected data was stored in a personal computer and the overall sensitivity, specificity, positive predictive value, negative predictive value and accuracy based on histological results (GS) of gastric biopsies. were calculated .

Definition of Variables: [11].

1-Sensitivity: is the probability of the diseased people to give (+ve) results or it is the capacity to show positivity of the actually diseased people. Sensitivity $=[$ True $(+v e) /$ True $(+v e)+$ False $(-v e)] * 100 \%$

2-Specificity: is the probability of the non-diseased people to give (-ve) results. Specificity= [True (- ve) / True $(- \text { ve) + False (+ve) }]^{* 100 \%}$

3-Accuracy: is the proportion of true results among all results.

Accuracy $=[$ True $(+v e)+$ True $(-v e) /$ True $(+v e)+$ False $(+v e)+$ False

(-ve)+True (-ve)]*100\%

4-Positive Predictive Value (P.P.V.):is the probability of people with (+ve)result to be diseased truly.

P.P.V.=[True(+ve) / True (+ve)+False $(+v e)]^{* 100 \%}$

5-Negative Predictive Value(N.P.V.): is the probability of people with (-ve ) result to be not diseased truly.

N.P.V.=[True(-ve) / False(-ve)+True(-ve)]*100\%

6-True (+ve) : clinically positive cases and positive histopathology . 
7-True (-ve) : clinically negative cases and negative histopathology .

8- False (+ve) : clinically positive cases and negative histopathology.

9- False(-ve): clinically negative cases and positive histopathology

\section{Results}

The study included (74) dyspeptic patients distributed as 26(35.14\%) females and $48(64.86 \%)$ males. The mean age of patients was 41.6 years [(42.85) years for females, (40.91) years for males], 58 (78.38\%) patients were married and the remaining $16(21.62 \%)$ of patients were single, $37(50 \%)$ patients were current smokers.

Regarding the origin of cases referral , $51(68.92 \%)$ of patients were referred from private clinics and the remaining $23(31.08 \%)$ were referred from outpatient clinics .

The age of the patients included in this study range form (20-70) years and the highest percentage of patients $(29.73 \%)$ were of younger age group (20-30) years as shown in figure (1).

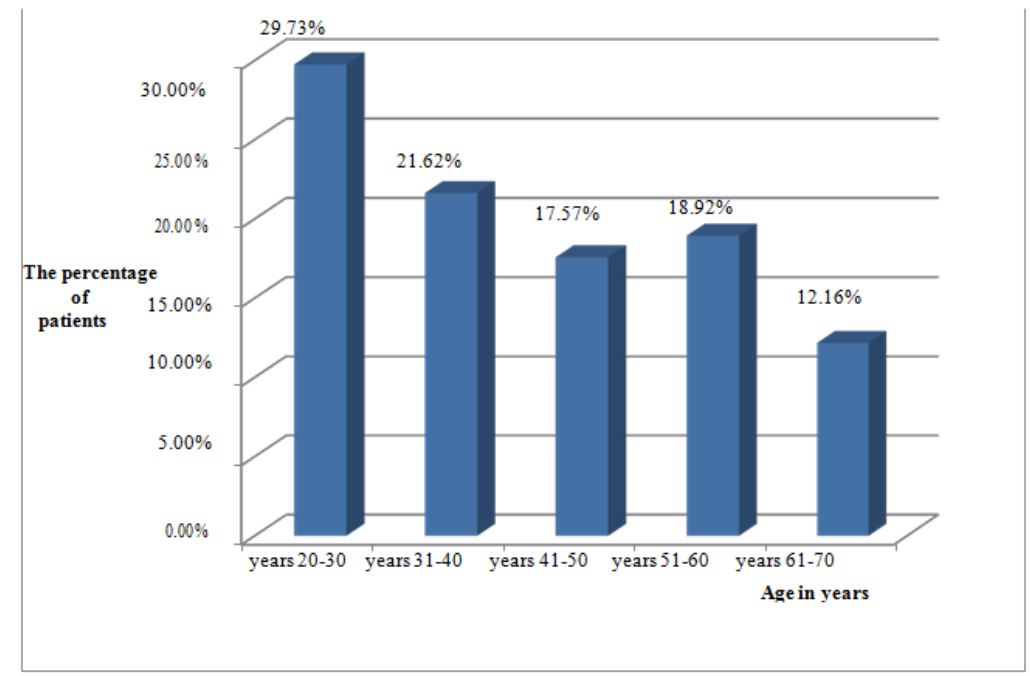

Figure(1)Distribution of studied sample regarding age.

According to the on s e $\mathrm{t}$ of disease, the highest percentage of patients $(45.95 \%)$ had the symptoms within one month and the lowest percentage of patients (1.35\%) had the symptoms within 3-4 months, as shown in table (1).

Table (1) Distribution of the studied sample regarding the duration of symptoms.

\begin{tabular}{|c|c|c|}
\hline $\begin{array}{c}\text { Time } \\
\text { (months) }\end{array}$ & $\begin{array}{c}\text { Number of } \\
\text { patients }\end{array}$ & Percentage \\
\hline$<1$ & 34 & $45.95 \%$ \\
\hline $1-2$ & 20 & $27.03 \%$ \\
\hline $2-3$ & 10 & $13.51 \%$ \\
\hline $3-4$ & 1 & $1.35 \%$ \\
\hline$>4$ & 8 & $10.81 \%$ \\
\hline
\end{tabular}

The distribution of patients regarding disease symptomatology, the result showed highest percentage of patients (55.45\%) had heart burn followed by epigastric pain during meal(52.7), as shown in table (2) . 
Table (2) . Distribution of the studied sample regarding the disease symptomatology.

\begin{tabular}{|l|l|l|}
\hline Disease symptomatology & Number of patients & Percentage \\
\hline Epigastric pain & 39 & $52.7 \%$ \\
\hline During meal & 31 & $41.89 \%$ \\
\hline At night & \multicolumn{2}{|l|}{} \\
\hline Aggravating factor & 36 & $48.65 \%$ \\
\hline Spicy food & \multicolumn{2}{|l|}{} \\
\hline Relieving factor & 31 & $41.89 \%$ \\
\hline Fasting & 19 & $25.68 \%$ \\
\hline Other symptom & 37 & $50 \%$ \\
\hline Nausea ,vomiting & 41 & $55.45 \%$ \\
\hline Loss of appetite & & \\
\hline Heart burn & & \\
\hline
\end{tabular}

Regarding endoscopic finding, the highest percentage of patients $(81.08 \%)$ had gastritis, distributed as $39(52.7 \%)$ patients with positive histopathology for $H$. pylori and $21(28.38 \%)$ patients with negative results as shown in table (3).

Table (3) . Distribution of the studied sample regarding the Endoscopic finding.

\begin{tabular}{|l|c|c|c|c|c|c|}
\hline Endoscopic & \multicolumn{2}{|l|}{$\begin{array}{l}\text { Nositive } \\
\text { histopathology }\end{array}$} & \multicolumn{2}{l|}{ histopathology } \\
\hline finding & 39 & $(52.7 \%)$ & 21 & $(28.38 \%)$ & 60 & $(81.08 \%)$ \\
\hline $\begin{array}{l}\text { duodenitis+ } \\
\text { gastritis }\end{array}$ & 5 & $(6.76 \%)$ & & & 5 & $(6.76 \%)$ \\
\hline $\begin{array}{l}\text { gastric-squamous } \\
\text { carcenoma }\end{array}$ & 1 & $(1.35 \%)$ & & & 1 & $(1.35 \%)$ \\
\hline $\begin{array}{l}\text { gastric- } \\
\text { adenocarcenoma }\end{array}$ & 2 & $(2.7 \%)$ & 3 & $(4.05 \%)$ & 5 & $(6.76 \%)$ \\
\hline $\begin{array}{l}\text { adenomatous } \\
\text { polyp }\end{array}$ & 1 & $(1.35 \%)$ & & & 1 & $(1.35 \%)$ \\
\hline duodenitis & & $(1.35 \%)$ & & & 1 & $(1.35 \%)$ \\
\hline $\begin{array}{l}\text { Hyperplastic } \\
\text { polyp }\end{array}$ & & 1 & $(1.35 \%)$ & 1 & $(1.35 \%)$ \\
\hline
\end{tabular}

The results of histopathological examination which considered as a gold standard test in this study, $49(66.22 \%)$ patients had $H$. pylori infection and the remaining $25(33.78 \%)$ patients had no infections while the results of ${ }^{14} \mathrm{C}$-UBT which considered as a test under evaluation, 40 (54.1\%) patients had $H$. pylori 
infection and the remaining $34(45.9 \%)$ patients had no infections.Difference between the two tests is 9 false negative results in the test, as shown in figure (2).

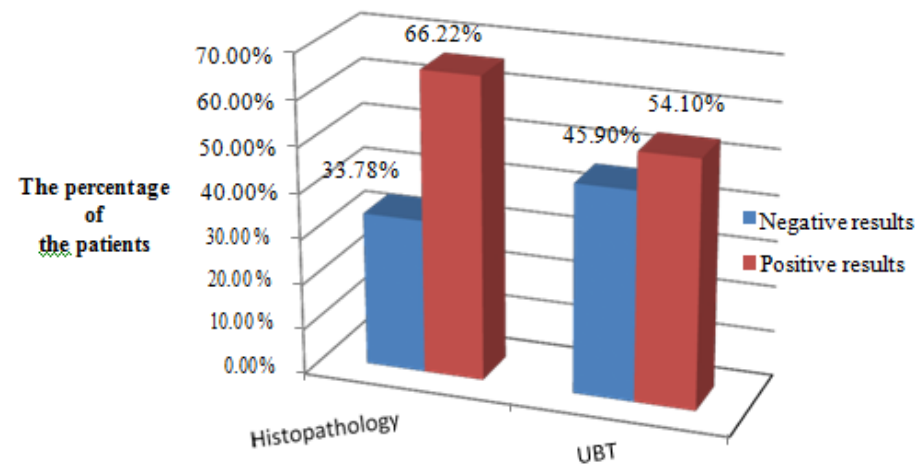

\begin{tabular}{|l|l|l|}
\hline Results & Endoscopic culture & Breath test \\
\hline positive & $49(66.22 \%)$ & $40(54.1 \%)$ \\
\hline Negative & $25(33.78 \%)$ & $34(45.9 \%)$ \\
\hline
\end{tabular}

Figure (2) The results of histopathology and 14C-UBT

The total number of patients who underwent histopathological examination and UBT was (74) patients, among them $\mathrm{H}$. pylori infection was confirmed in $49(66.22 \%)$ patients by histopathological examination ,but by ${ }^{14} \mathrm{C}$-UBT there was $40(54.1 \%)$ patients.

So the sensitivity, specificity, accuracy, positive predictive value and negative predictive value (81.63\%), (100\%), (87.84\%), (100\%) and (73.53\%) respectively.

\begin{tabular}{|l|l|l|l|}
\hline \multirow{2}{*}{14 C-UBT } & \multicolumn{2}{|l|}{ Gold standard test } & \multirow{2}{*}{} \\
\cline { 2 - 4 } & positive & negative & \\
\hline positive & $($ TP)a & $($ FP)b & a+b= \\
& 40 & 0 & 40 \\
\hline negative & $($ FN)c & $($ TN $) d$ & $c+d=$ \\
& 9 & 25 & 34 \\
\hline total & a+c=49 & b+d=25 & 74 \\
\hline
\end{tabular}

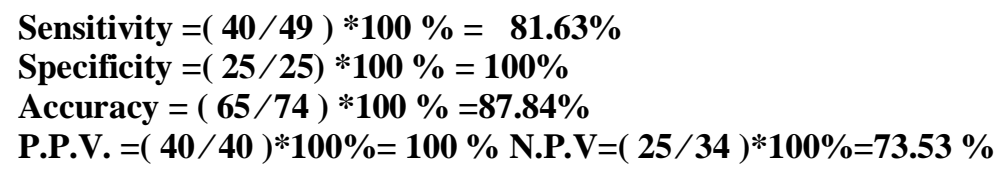

\section{Discussion}

Current guidelines for the management of $\mathrm{H}$. Pylori infection recommend eradication treatment without performing endoscopy in patients under 45 years of age who have no remarkable symptoms [12-14]. The use of 
noninvasive tests has been advocated in different strategies for management of dyspeptic patients in the primary care based on clinical and economical analyses $[15,16]$.

Invasive diagnostic tests for $H$ Pylori diagnosis need gastroscopy that requires sedation and monitoring during the procedure by trained staff and expertise. These diagnostic tests are costly and require an established healthcare infrastructure.

In practical terms, invasive tests for the diagnosis of $H$. Pylori are not feasible, especially in less developed countries. An economical, reliable and office based diagnostic test is therefore, more appropriate in settings of under privileged and cost constraint societies.

Other factors that determine choice of diagnostic tests apart from accuracy, in primary care setting include the availability of test, ease to perform, cost, self-sufficiency and acceptance by the patients. The present study has shown that microdose 14C UBT has the majority these features. The male

to female ratio was 1.81:1.This male predominance is in agreement with the finding of Rasool et al [17]. and Reza et al[18]. and contradict the findings of study conducted in Iran [Fariborz et al ] [19]. which found female dominance.

The mean age of patients was 41.6 years. This finding is comparable with the results of (Reza etal) [18] and (Laimas et al) [20].

According to the final diagnosis, in this study the highest percentage of patients had gastritis. This finding is comparable with the results of (Reza et al) [18]. This study has demonstrated a high accuracy of microdose 14C-UBT for the detection of $H$. Pylori infection comparable to histological diagnosis of $H$. Pylori. The 14C-UBT has $81.63 \%$ sensitivity, $100 \%$ specificity, $100 \%$ PPV, $73.53 \%$ NPV, and $87.84 \%$ accuracy, compared with histopathological examination (GS). These findings are compatible with Rasool et al.'s study. regarding histopathology alone as GS, Ninety-four consecutive patients with dyspeptic symptoms undergoing gastroscopy were enrolled. Heliprobe sensitivity, specificity, NPV, PPV, and accuracy were 92\%, 93\%, 84\%, $97 \%$, and $93 \%$, respectively, which were consistent with our gold standard test. [17]. In another study, conducted by Öztürk et al, that is again regarding only histopathology as GS (a prospective study was conducted in Turkey) [21]. A 75 patients with dyspeptic symptoms undergoing gastroscopy were enrolled. Heliprobe had higher sensitivity (100\%), but with lower specificity (76\%).

In this study the cause of low accuracy in comparison from other studies is the false negative results. It could be explained that UBT becomes false negative during treatment with antacid and antibiotics [22, 23], so poor compliance and antibiotics and antacid abuse from patients cause this false negative results. However, it has been observed recently that addition of citric acid in the urea capsule may diminish the negative effect of acid inhibitory drugs on the accuracy of 14C UBT[24]. Although an acidified 14C urea capsule (Helicap) was used, discontinue antacid medications for at least two weeks before the test was preferred.

\section{Conclusions}

1) $14 \mathrm{C}$ UBT is easy, simple and cheap non-invasive test for supporting the diagnosis and monitoring for the treatment of $H$. pylori infection.

2) $14 \mathrm{C}$ UBT showed high sensitivity rate, specificity rate, accuracy rate, and positive predictive value and low negative predictive value.

\section{Recommendations}

1)14C-Urea Breath test could be used in the early diagnosis of $H$. pylori infection and subsequently reduce complication rates.

2) The uses of this test in the diagnosis of $H$. pylori infection should be conducted in proper way to prevent false results and thus low accuracy.

3) It is very handy in primary health care centers and peripheral hospitals where invasive tests are sparse.

\section{References}

[1]- C S Goodwin and B W Worsley, Microbiology of Helicobacter pylori, Gastroenterology Clinics of North America, (22), 1993, 519.

[2]- G V, Papatheodoridis, S Sougioultzis , and A J Archimandritis, Effects of Helicobacter pylori and non steroidal anti inflammatory drugs on peptic ulcer disease: a systematic review, Clinical Gastroenterology and Hepatology, (4), 2006, 130-142.

[3]- J Q Huang, S Sridhar, S Chen and R H Hunt, Meta-analysis of the relationship between Helicobacter pylori seropositivity and gastric cancer, Gastroenterology, (114), 1998,1169-1179.

[4]- A Papa, G Cammarota, A Tursi, A Gasbarrini, and G Gasbarrini, Helicobacter pylori eradication and remission of low-grade gastric mucosa-associated lymphoid tissue lymphoma: a long-term follow-up study, Clinical Gastroenterology, (31), 2000, 169-171.

[5]- R Pounder, E and D Ng, The prevalence of Helicobacter pylori infection in different countries, Alimentary Pharmacology and Therapeutics, (9), 1995, 33-39.

[6]- N R Hussein, Helicobacter pylori and gastric cancer in the Middle East: a new enigma? .World Journal of Gastro enterology, (26), 2010, 3226-3234.

[7]- $\quad \mathrm{N}$ Vakil, D Rhew, A Soll, and J Ofman, The cost effectiveness of diagnostic testing strategies for Helicobacter pylori, American J of Gastroenterology, (95), 2000, 1691-1698. 
[8] - WD Chey, Accurate diagnosis of Helicobacter pylori. 14C urea breath test, Gastroenterology Clinics of North America, (29), 2000, $895-902$.

[9]- E Öztürk, Diagnostic methods of Helicobacter pylori infections, Gülhane Tıp Dergisi, (50), $2008,60-64$.

[10]- S Leide-Svegborn., K Stenstrom ,M Olofsson, S Mattsson, L Nilsson ,B Nosslin .Biokinetics and radiation doses for Carbon-14 urea in adults and children undergoing the Helicobacter pylori breath test, European J of Nuclear Medicine,26(6) , ( 1999), 573580 .

[11]- OA Lucas. Public health medicine for the tropics .Short text book. Fourth edition . International student's edition .Arnold. ,(4), 2003,199-215.

[12]- Current European concepts in the management of H.pylori infection. The Maastricht Consensus Report. European H.pylori Study Group.Gut,(41), 1997,8-13.

[13]- The report of the Digestive Health Initiative SM International Update Conference on H. pylori. Gastroenterology, $1997 ; 113$.

[14]- SK Lam, NJ Talley. Report of the1997Asia Consensus Conference on the management of H. pylori infection. J Gastroenterol Hepatol (13), 1998, 1-12.

[15]- CM Pathak, DK Bhasin, KL Khanduja. Urea breath test for H. pylori detection: present status. Trop Gastroenterol, (25), 2004, 156161 .

[16]- KE McColl, LS Murray, D Gillen, A Walker, A Wirz, J Fletcher, C Mowat, E Henry, A Kelman, A Dickson. Randomised trial of endoscopy with testing for $H$. pylori compared with non-invasive $H$. pylori testing alone in the management of dyspepsia. BMJ, (324), 2002, 1999-1002.

[17]- S Rasool, S Abid, W Jafri. 14C UBT for H. Pylori diagnosis. World J Gastroenterol, 13(6), 2007,925-929.

[18]- D Reza, K Ali., B Davood., E Mohammad, H Mohammad., K Mohammad. Microdose 14C -UBT for the diagnosis of H. pylori: A Survey in Iranian population, Daru, ( 13),2005,6-12.

[19]- M Fariborz, S Omid, J Farahnaz, Clinical Study, Clinical Validation of an Office-Based 14C-UBT (Heliprobe) for H. pylori Diagnosis in Iranian Dyspeptic Patients. Gastroenterology Research and Practice. (Article), 2011, 5 pages.

[20]- V Laimas, K Gediminas, K Limas . Evaluation of a novel 14C-urea breath test "Heliprobe" in diagnosis of Helicobacter pylori infection. Medicine, 43(1). 2007, 32-5.

[21]- E Öztürk, Z Yesilova , S Ligan, N Arslan, A Erdil , B Celasun et al .Low dose 14 C-UBT for the diagnosis of $H$. pylori infection. Eur J Nucl Med, (30), 2003, 1457-1462.

[22]- DY -Graham, AR Opekun, F Hammoud, Y Yamaoka, R Reddy, MS Osato, HM El-Zimaity. Studies regarding the mechanism of false negative urea breath tests with proton pump inhibitors. Am J Gastroenterol, (98), 2003.1005-1009.

[23]- DY Graham DY, AR Opekun M, Jogi, Y Yamaoka, H Lu, R Reddy, HM El-Zimaity. False negative urea breath tests with H2receptor antagonists: interactions between $H$. pylori density and pH. Helicobacter. 2004; 9(1): 17-27.

[24]- WD Chey, KV Chathadi, J Montague, F Ahmed, U Murthy. Intragastric acidification reduces the occurrence of false negative urea breath test results in patients taking a proton pump inhibitor. Am J Gastroenterol (96). 2001, 1028-1032. 